\title{
Second-Year Enhancements to a Summer Faculty Immersion Program
}

\section{Dr. Juan C. Morales, Universidad del Turabo}

Dr. Juan C. Morales, P.E., joined the Mechanical Engineering Department at Universidad del Turabo, Gurabo, Puerto Rico, in 1995. He has been Department Head since 2003. Dr. Morales also served as the ABET Coordinator of the School of Engineering between 2003 and 2010. As ABET Coordinator, Dr. Morales had the privilege of working closely with the entire engineering faculty in the process of establishing a systemic and sustainable Outcomes Assessment Program. Dr. Morales led the effort to obtain the initial ABET accreditation (EAC) for all four engineering programs. His current research explores innovations in the classroom and their diffusion.

Dr. Michael J. Prince, Bucknell University 


\title{
Second-Year Enhancements to a Summer Faculty Immersion Program
}

\author{
Dr. Juan C. Morales \\ Universidad del Turabo \\ Dr. Michael J. Prince \\ Bucknell University
}

\begin{abstract}
This paper describes the enhancements that were implemented in the 2013 edition of a Summer Faculty Immersion Program (SFIP). The SFIP is a five-year, externally funded, faculty development program that started in 2012 and runs until 2016. The intention of the program is to ignite the use of innovative and effective teaching practices in a manner that will promote lasting change in engineering and physics faculty. The SFIP takes place during the month of June and provides a stipend to participants. It is divided into an intensive one-week training workshop that is followed by a three-week immersion where each faculty member transforms two courses. An expected transformation is the selection and adaptation of real-world examples that are presented at the beginning of class to establish the need for learning the course material (inductive approach). The problems are subsequently solved using the principles and theory taught in class. When possible, real-world examples that can be brought into class - a bicycle, for example - are preferred since they intensify student engagement and interactions. The paper starts by grounding the SFIP within Everett Rogers' theoretical framework of diffusion of innovations. It then presents a short summary of the SFIP to provide context for understanding the second-year enhancements. The enhancements include the following: training on writing learning outcomes at a granular level; training on Bloom's taxonomy and their relationship to learning outcomes; a presentation of gamification techniques that can be transferred to the classroom; an overview of Massive Open Online Course (MOOCs) and their potential use for "flipping the classroom". Faculty were also requested to perform the following: create a panoramic outline (divide each course into 30 class sessions) prior to starting the SFIP in June; write granular learning outcomes for each and every class session during the SFIP; and prepare a review sheet for students per exam that is based on the learning outcomes created during the SFIP. Partial results of the SFIP are also provided.
\end{abstract}

\section{Introduction}

The Summer Faculty Immersion Program (SFIP) strives to ignite and sustain innovative classroom practices in engineering and physics courses in a manner that will promote lasting change in the faculty. In essence, the SFIP has been proposed as a mechanism to diffuse engineering education innovations in the classroom. Diffusion of educational innovations is a challenge that has defied a satisfactory solution for decades as evidenced by the many references 
in the literature; for example, Borrego [1] states that "despite decades of effort focused on improvement of engineering education, many recent advances have not resulted in systemic change". The Research Council of the National Academies' report on transforming STEM education [2] states that support is required to implement "innovative STEM course development that exceeds substantially the normal course preparation commitment". It also states: "The authoring committee recognizes that implementing the visions of this report could require new funds or shifts in the allocation of resources." Felder and Hadgraft [3] state "We believe that if engineering education research were stopped completely right now (which we are in no way advocating), and engineering faculties could be induced to put into practice everything we currently know about teaching and learning from past research, cognitive science, and experience, then we would achieve innovation with impact to an extent beyond the wildest dreams of the most idealistic reformers. The question then becomes, how can we do that?". The SFIP endeavors to provide an answer to this last question. It is a work in progress and this paper summarizes the current status of the project.

\section{Diffusion of Innovations}

In the book Diffusion of Innovations, the author Everett Rogers [4, page 5] states that diffusion "is a kind of social change, defined as the process by which alteration occurs in the structure and function of a social system." Furthermore, diffusion is defined as "the process by which an innovation is communicated through certain channels over time among the members of a social system." The four main elements that influence the spread of a new idea are, according to Rogers: the innovation, communication channels, time, and a social system. These four elements are found in every diffusion program. The SFIP incorporates these elements as follows:

\section{The innovation}

There are two levels of innovation at play in the SFIP. The first level is represented by all the excellent engineering education research that has been performed to date that has resulted in innovations that could be diffused into the classroom. The second level is the SFIP itself, that is, the SFIP as a mechanism for diffusing the innovations.

The communication channels

Communication channels are the means by which messages get from an individual trying to communicate an innovation to a receiver that does not yet have knowledge of the innovation. The diffusion of classroom innovations in the SFIP has three distinct communication channels; these are:

1. The channel between the SFIP external consultant (second author), an experienced researcher and practitioner of engineering education reform, and the 
faculty participants. This channel opens up with a two-day workshop offered by the external consultant at the beginning of each SFIP session. The channel is kept open for additional communication at any time via email or other convenient form.

2. The channel between the SFIP director (first author), who is a faculty member and department head at the institution where the SFIP is being implemented, and the faculty participants. The SFIP Director provides continuous support and guidance to the faculty participants during all phases of implementation. He also conducts assessment to determine the level of implementation.

3. The channel between the faculty participants themselves as they informally compare and share ideas and experiences. Although informal, it is a critical channel as it has been shown that "most people depend mainly upon a subjective evaluation of an innovation that is conveyed to them from other individuals like themselves who have previously adopted the innovation." [4, page 18]. Rogers continues this thought in the same page by stating "This dependence on the communicated experience of near-peers suggests that the heart of the diffusion process is the modeling and imitation by potential adopters of their network partners who have adopted previously."

A fourth communication channel - the channel between the SFIP director (first author) and the external consultant (second author) - is vital for researching, developing, maintaining, and sustaining the structure of the SFIP as a diffusion mechanism. The SFIP is not a static idea but a dynamic one that requires adjustments and enhancements over time as it faces obstacles and evolves to overcome them. It is evidently a very hard problem to solve.

$\underline{\text { Time }}$

There are two distinct time dimensions that come into play in the SFIP; these are:

1. The one-month time dimension (each SFIP summer period). The summer period is the heart of the SFIP. It is the igniter of the diffusion process. As explained in the next section, the SFIP consists of a one-month summer immersion that is conducted while the faculty participants are free from other commitments such as summer research or summer teaching. A new group of seven faculty members are trained every summer for the duration of the grant. They learn about classroom innovations during workshops and then adapt these innovations to two of their courses. A distinct feature of the SFIP is the time provided to the faculty to transform their courses, including a stipend. Most diffusion models only include workshops with the expectation that the faculty must transform their courses on 
their own time. As stated previously, the National Research Council has recognized that the development of course innovations requires an amount of time that "exceeds substantially the normal course preparation commitment" [2].

2. The 10-year time dimension (the five-year grant period and beyond). During the first five years, the grant will provide funds to conduct five SFIP summer sessions. All the engineering and physics faculty members shall have participated by year 2016. Within this 5-year period, the authors will have time to evaluate the results of the program and recommend enhancements and improvements to try to reach a high level of achievement. The additional five years beyond the grant period is an educated guess of the time that will be required to truly achieve full adoption of the innovations at this institution. The educated guess is based on two elements. The first one is based on the personal experience of the first author who, as ABET Coordinator of the School of Engineering, was responsible for designing and creating a sustainable outcomes assessment program that achieved $100 \%$ engineering faculty participation at this institution [5]. It took seven uninterrupted years of persistent effort to reach the current level of "faculty culture" that sustains this program in a stable manner. The second element is based on the research finding that it takes 10 years of active engagement to become an expert in any domain, even for the most talented individuals [6, p.412; as quoted in 7]. Clearly, it takes patience and persistence to reach a high level of achievement. After the grant period, all the faculty members will be monitored longitudinally as part of the outcomes assessment program of the School of Engineering, as each one of them is induced to reach a high level of expertise with the classroom innovations. Additional assessment instruments are being designed and developed at this time by the authors to improve the measurements.

\section{The social system}

"The social system constitutes a boundary within which an innovation diffuses" [4, page 24]. There is an outer boundary to the social system encompassed by the institution in which the SFIP is being implemented. Within the outer boundary are two internal boundaries constituted by the School of Engineering (engineering faculty) and the School of Science and Technology (physics faculty). The social structure of both schools is similar, with some exceptions. Perhaps the biggest difference has to do with the level of "faculty culture" regarding outcomes assessment. While the engineering faculty have reached a high and stable level of conducting direct and indirect assessment as a response to ABET's accreditation criteria, the physics faculty lag significantly in this respect, perhaps because their programs are not held to a similar level of scrutiny for accreditation. A strong culture of assessment is a very good prerequisite to have before initiating a program like the SFIP as it exposes the faculty to the shortcomings in their courses. In fact, it was the outcomes assessment results from the School of Engineering that 
motivated the proposal that landed this grant. The SFIP is a response to the students' suggestions that more practical problems should be included in the curriculum to provide context to the theory presented in the classroom.

Also, the institution itself, as a norm, sponsors innovation and the pursuit of excellence so that the SFIP is conducted within a social system in which the upper echelons of leadership support it. This is fortunate as, regarding this point, Everett Rogers starts his book [4,page 1] with the following quote by Niccolo Machiavelli from The Prince (1513): "There is nothing more difficult to plan, more doubtful of success, nor more dangerous to manage than the creation of a new order of things. . Whenever his enemies have occasion to attack the innovator they do so with the passion of partisans, while the others defend him sluggishly so that the innovator and his party alike are vulnerable." The SFIP director (first author) is a member of the social system (professor and department head) and knows well all the faculty members of the school by virtue of having served as the ABET Coordinator for the initial ABET accreditation of all its engineering programs. The consultant (second author) is external to the social system and is highly regarded by the system as an expert in engineering education reform. As a result, the faculty members show a high level of interest and motivation to participate in the workshops.

\section{Overview of the Summer Faculty Immersion Program}

References [8] and [9] provide a detailed description of the SFIP. This section restates some of the material to provide context for discussing the second year enhancements of the program.

The SFIP, as implied by its name, focuses the faculty development effort during the summer (the entire month of June), while the faculty members are free from their regular duties of a typical semester. Funding is addressed through a grant from the US Department of Education which provides to each participating faculty member a $\$ 7,500$ summer stipend, a $\$ 2,500$ budget to purchase educational materials, and a $\$ 2,000$ travel budget to be used for additional professional development. The stipend provides an incentive to ensure that the faculty will concentrate their efforts only on course innovations during the month of June (no summer teaching or research), and that the faculty will commit to the implementation of the innovations in subsequent semesters. Funding runs through 2016 and the budget includes all the faculty members from the School of Engineering (Computer, Electrical, Industrial, and Mechanical engineering programs). It also includes the physics faculty that are responsible for the Physics I and II courses that are required for all engineering students. A total of 35 faculty members will participate by 2016 at a rate of seven faculty members per summer session. The expected changes are systemic by virtue of including all the faculty members of the school. In terms of ensuring faculty participation in the program, a survey by Morales [10] showed that $96 \%$ of the 
faculty at this institution were receptive to learning and adopting transformative teaching strategies that are based on engineering education research results.

The time distribution during the SFIP in June is provided in Figure 1.

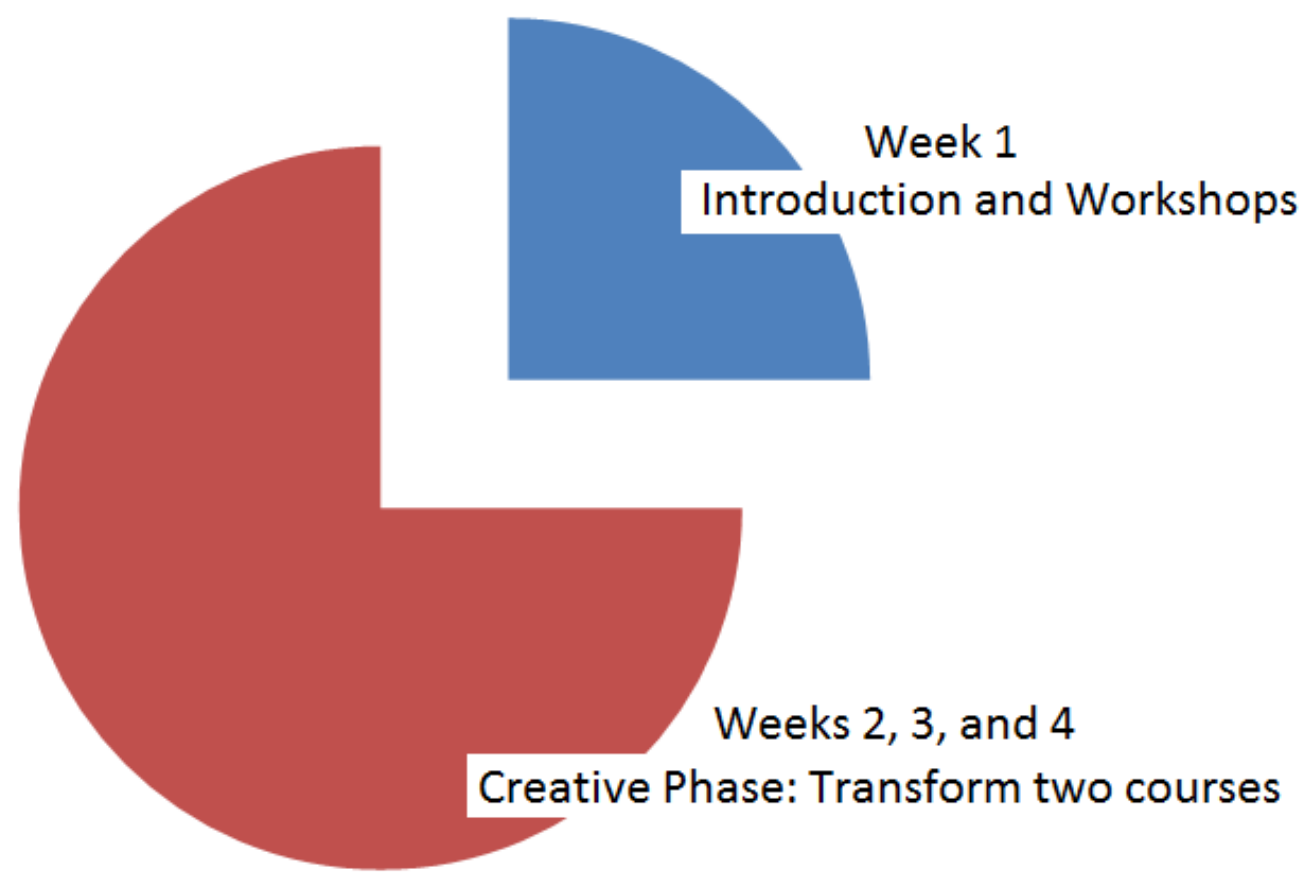

Figure 1: Time distribution during the summer program (month of June)

The first week includes an on-site visit by the second author to provide workshops over a two-day or three-day period, depending on scheduling issues. When given over two days it overextends the typical workday. The first week also includes additional workshops provided by the first author. Table 1 includes the topics of these workshops. The topics that were new to the SFIP are check marked. The last three weeks are dedicated to the transformation of two courses by each faculty member. This three-week period is a prominent characteristic of the SFIP. As indicated earlier, most diffusion models only include workshops with the expectation that the faculty must transform their courses on their own time. However, the National Research Council has recognized that the development of course innovations requires an amount of time that "exceeds substantially the normal course preparation commitment" [2]. 


\section{Table 1: Workshop topics provided during Week 1 (The checked items $\{\checkmark\}$ are enhancements)}

\begin{tabular}{|c|c|}
\hline $\begin{array}{l}\text { Topics presented by the Second Author } \\
\text { (first presenter) }\end{array}$ & Topics presented by the First Author \\
\hline $\begin{array}{l}\text { 1. Presentation - On writing effective } \\
\text { instructional objectives }\{\checkmark\} \text {. Full } \\
\text { day. }\end{array}$ & 16. SFIP 2013 Kick-off Presentation \\
\hline $\begin{array}{l}\text { 2. Presentation - Making the Transition } \\
\text { to Active Learning }\end{array}$ & $\begin{array}{l}\text { 17. ASEE } 2013 \text { Paper on Summer Faculty } \\
\text { Immersion: First year results }\{\boldsymbol{V}\}\end{array}$ \\
\hline 3. How about a quick one? & $\begin{array}{l}\text { 18. HETS } 2012 \text { Paper on SFIP: Potential to } \\
\text { Transform Engineering Education }\end{array}$ \\
\hline $\begin{array}{l}\text { 4. Incorporating the } 5 \text { tenets of } \\
\text { Cooperative Learning: Sample } \\
\text { Activities to Promote Each Tenet }\end{array}$ & $\begin{array}{l}\text { 19. Bloom and Krathwol Definitions of Levels } \\
\text { and McGeath Action Verbs }\end{array}$ \\
\hline 5. Peer Rating Factor & 20. Examples from SFIP 2012 session $\{\boldsymbol{\checkmark}\}$ \\
\hline $\begin{array}{l}\text { 6. Review Sheet for Quiz } 1 \text { listing the } \\
\text { objectives for the Quiz }\end{array}$ & $\begin{array}{l}\text { 21. } \mathrm{E}^{3} \text { : Using Everyday Engineering Examples in } \\
\text { the classroom }\end{array}$ \\
\hline 7. CHEG300: Self-Assessment & $\begin{array}{l}\text { 22. Innovation: Ranking Tasks for Mechanics of } \\
\text { Materials }\{\boldsymbol{V}\} \text {. (On achieving expertise) }\end{array}$ \\
\hline $\begin{array}{l}\text { 8. Characteristics of Good Problems for } \\
\text { Problem Based Learning }\end{array}$ & 23. Innovation: Physics I MOOC (Coursera) $\{\checkmark\}$ \\
\hline 9. CHEG300 Problem 1 & $\begin{array}{l}\text { 24. Innovation: Gamification MOOC (Coursera) } \\
\{\downarrow\}\end{array}$ \\
\hline $\begin{array}{l}\text { 10. Homework Grading Sheet: } \\
\text { Description of Homework Grades }\end{array}$ & $\begin{array}{l}\text { 25. Innovating the Exams and Grading } \\
\text { Distributions }\{\boldsymbol{\checkmark}\}\end{array}$ \\
\hline 11. PBL Steps & \\
\hline $\begin{array}{l}\text { 12. Inductive Teaching and Learning } \\
\text { Methods: Definitions, Comparisons, } \\
\text { and Research Bases }\end{array}$ & \\
\hline $\begin{array}{l}\text { 13. Does Active Learning Works? A } \\
\text { Review of the Research }\end{array}$ & \\
\hline $\begin{array}{l}\text { 14. Objectively Speaking } \\
\text { 15. We never said it would be easy... }\end{array}$ & \\
\hline
\end{tabular}

\section{Enhancements to the SFIP}

The enhancements include the following: training on writing learning outcomes at a granular level; training on Bloom's taxonomy and their relationship to learning outcomes; a presentation of gamification techniques that can be transferred to the classroom; an overview of Massive Open Online Course (MOOCs) and their potential use for "flipping the classroom". Faculty were also requested to perform the following: create a panoramic outline (divide each 
course into 30 class sessions) prior to starting the SFIP in June; write granular learning outcomes for each and every class session during the SFIP; and prepare a review sheet for students per exam that is based on the learning outcomes created during the SFIP.

\section{$\underline{\text { Writing effective learning outcomes }}$}

The first session of the SFIP in the summer of 2012 did not include a presentation by the second author on writing effective learning outcomes. It only included topics on active teaching and learning, with emphasis on the inductive methodology. The omission was at the request of the first author. The reason was that the faculty had worked very hard on creating learning outcomes for their courses (approximately 10 per course) as part of the effort of creating the outcomes assessment program for initial ABET accreditation. These learning outcomes were also used as the performance criteria for assessment. The first author reasoned that a workshop on this topic was not necessary. However, at the conclusion of the 2012 workshop it became clear that the material on writing effective learning outcomes was extremely important and should not be left out from the workshops. The inductive methodology requires a very fine level of granularity regarding the learning outcomes. What is it exactly that we, as faculty members, wish the students to learn? Ten learning outcomes is not enough. The outcomes must be broken down to a finer level of granularity. In the 2013 workshop, the presentation on writing effective learning outcomes was very well received by the audience. As a result, each faculty member prepared approximately 100 learning outcomes for each of their two courses by the end of the SFIP 2013 session. These same learning outcomes are handed out to students so that they know exactly what is expected from them. The question for the faculty member then becomes how to most effectively succeed in fulfilling the learning experience of the students. This question set the stage for the presentation on the inductive methodology of teaching and learning.

\section{Bloom's taxonomy of the Cognitive Domain}

Although the faculty at this institution was aware of Bloom's taxonomy [11], and they have used the action verbs associated with each level, the specific and direct mention of each of its six levels has not yet been worked into the learning outcomes of the courses. The six levels are:

1. Knowledge

2. Comprehension

3. Application

4. Analysis

5. Synthesis

6. Evaluation 
Bloom's taxonomy becomes particularly useful when dealing with a large number of learning outcomes, as in the approximately 100 outcomes that each faculty member generates for each of their two courses. It assists the faculty in setting priorities and ensuring "coverage of material" at an appropriate level. High-priority topics can be addressed through most of the six levels while lower-priority topics may stay at the lower levels. There will only be a few learning outcomes at the higher levels, while most of them will be concentrated at the lower levels. For example, in a heat transfer class, students may be expected to design a heat exchanger (level 5: Synthesis) and use their judgment and analysis to recommend the most appropriate design option, such as diameter vs. length issues (level 6: Evaluation). To achieve these two learning outcomes will require very many outcomes at the lower levels of the taxonomy. For example, the student must be able to list the different heat transfer mechanisms list (level 1: Knowledge); explain each one of them in their own words (level 2: Comprehension); be able to recognize in a real-world situation the mechanisms of heat transfer that are taking place (level 3: Application); and be able to use the basic principles and formulas to model and analyze mathematically a heat transfer process (level 4: Analysis). When the professor continues asking, what is it exactly that the students need to learn?, many more outcomes are generated at the lower levels to, for example, address the details of each heat transfer mechanism.

The beauty of the inductive methodology is that it starts with the higher levels of Bloom's taxonomy. For example, the class will start from day one by asking students to design a heat exchanger for a specific real-world application. Knowing the purpose of their learning increases the engagement of the students. The class will develop from that basic requirement. Citing from a medical journal [12], Prince and Felder [13] state that "A well-established precept of educational psychology is that people are most strongly motivated to learn things they clearly perceive a need to know. Simply telling students that they will need certain knowledge and skills is not a particularly effective motivator".

The use of Bloom's taxonomy is an excellent means to fully plan a class. Class topics which are marginal to the priority outcomes may be "covered" at the lower levels of the taxonomy or eliminated altogether. In turn, these lower priority outcomes could be left for the end of the term when time becomes a premium and there may be a rush to ensure "material coverage".

\section{Gamification techniques applied to the classroom}

Gamification is the ability of applying game elements and game design techniques to non-game contexts [14].

The material in this section was learned by the first author while enrolled in a free Massive Open Online Course (MOOC) offered by Coursera titled Gamification [15] which was 
taught by Dr. Kevin Werbach of the University of Pennsylvania. The MOOC was offered in a six-week period between April and May, 2013. The principal objective for enrolling was to identify gamification elements that could be transferred to the classroom and offered as a workshop for faculty during the summer. Some of the material from the class is presented in this paper but within the context of transferring the ideas to the classroom. The transference ideas are original work. For the transference, students are analogous to the game players, and the faculty is analogous to the game designers. Models that have been developed through research to understand how gamers think are then applied to the classroom. The psychology end of the course was the most useful.

The following four gamification concepts were selected and presented to the faculty as a workshop during the first week of the SFIP.

1. Flow - Citing from the course transcripts by Dr. Werbach, available in the course wiki [16], "The idea of flow is that there is a state that we sometimes get into where we are so engaged in what we are doing that time seems to lose its meaning. We lose ourselves in the activity. We are fully and completely engaged to the fullest our of our abilities."

The faculty should think constantly about the level of difficulty of the material that is being presented to students. If it is too hard, and is not broken down into pieces that are easier to digest, the student will become anxious. If the material is too easy, the student will become bored. Flow lies in the middle. The challenges must be ramped up with time to keep the students in the flow channel of learning. The flow model by Csikszentmihalyi [17]is summarized in Figure 2.

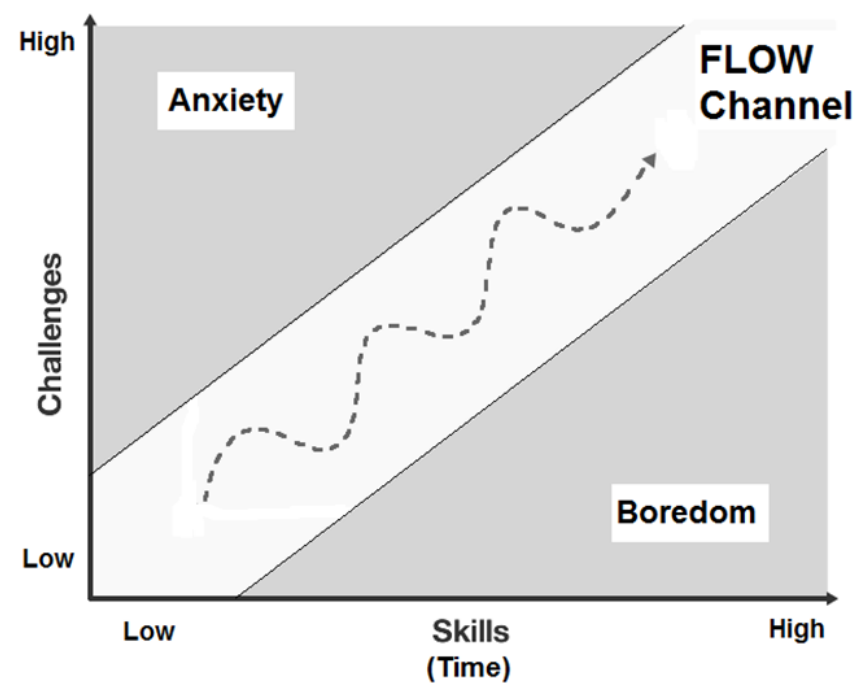

\section{Conditions for Flow:}

1. Clear goals.

2. Balance between perceived challenges and perceived goals.

3. Clear and immediate feedback

Figure 2: The flow model created by Csikszentmihalyi (adapted from http://scienceandvalues.wordpress.com ) 
2. Engagement Loops - The following cite from the course transcripts by Dr. Werbach, available in the course wiki [16], addresses the engagement loop as applied to an internet site "An engagement loop is the constant process of first motivators appearing. The game gives the user something to do, some reason to be motivated and to take an action that overcomes a challenge... to go and do something in the game. And then the motivation, if it's strong enough, effective enough, will lead to the action. Maybe it won't, at which point the loop dies but then another motivator comes up. And then at that point the user takes the action. They want to get the points to get to the reward offered by the game. So, they go and spend time on that part of the site. That's the action. And then the user gets feedback. Once again, the importance of the user having clear, direct and immediate feedback on what they're doing. Seeing the points they've accomplished, they have received. Seeing the level of their performance, that, in and of itself then becomes a motivator. So, that's why this is a loop. The action produces the feedback, the feedback becomes a form of motivation, the motivation leads to more actions. So, designing a gamified site involves structuring the way that, that loop happens.

An important aspect of engagement loops for teaching purposes is to provide immediate feedback to students. If the feedback is designed to be positive (for example, asking for a "one-minute paper" on the material that was just presented in class, and assign a portion of the grade to that activity) it will lead to motivation of the students. If they are motivated, then they will take another action (move to a different outcome and learn it), which leads to another immediate feedback, etc.. It gets them into the Flow Channel discussed above. The engagement loop is presented in Figure 3.

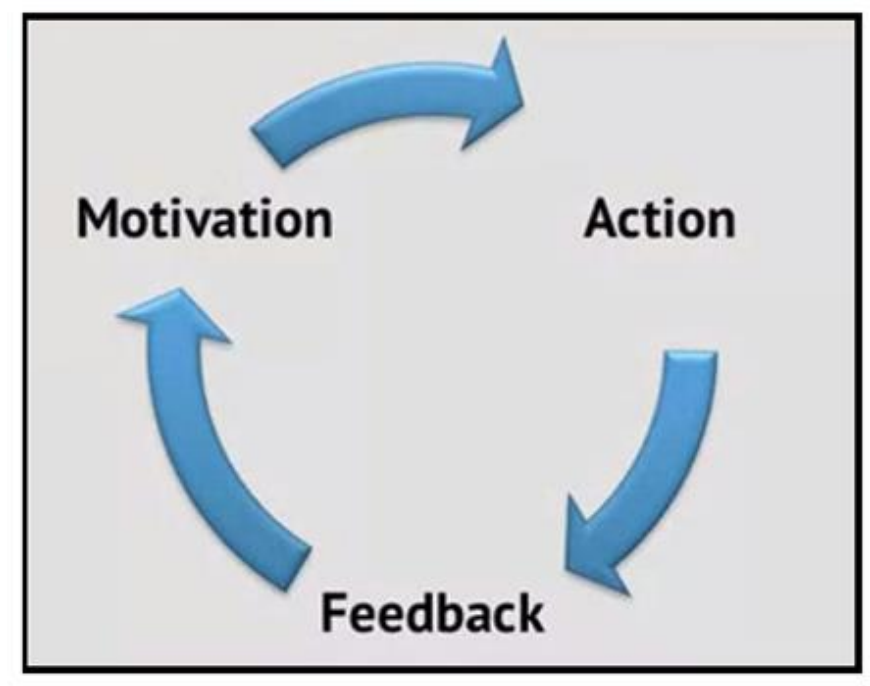

Figure 3: Engagement Loop

(https://www.coursera.org/course/gamification) 
3. Progression Loops - Relates to the progression in ability from newbies to masters of the material that one is teaching as students move in the Flow Channel. The overall objective (in red in Figure 4) is presented to students; for example, by the end of the semester the student shall be able to design a heat exchanger. However, it is not expected that students will get from start to finish in one big leap. Intermediate steps (in blue, in Figure 4) are designed to get students onboard, challenge them to climb the steep path of knowledge, then rest, then repeat the process progressively with another intermediate step until the overall objective is reached (Figure 5). Each of these steps may be addressed with a learning outcome at the appropriate level of Bloom's taxonomy.

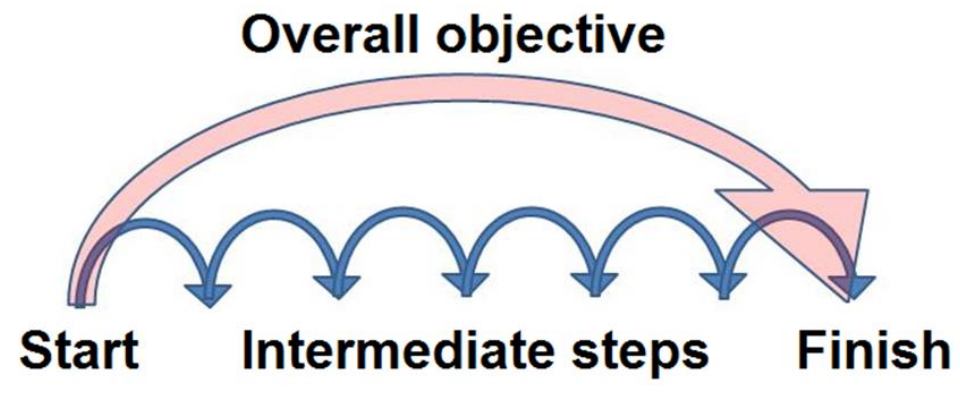

Figure 4: Progression Loop

(https://www.coursera.org/course/gamification)

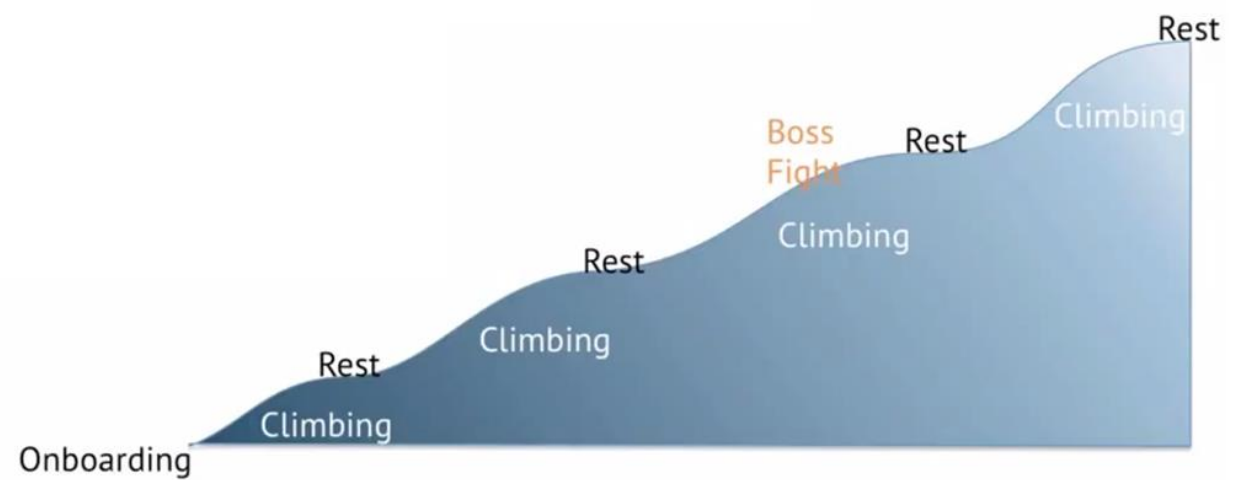

Figure 5: Player Journey on a Progression Loop

(https://www.coursera.org/course/gamification)

4. Fogg model for human behavior change - In the Fogg model [18], action will be taken if there is a correct temporal combination of motivation, ability and a trigger that induces the user to take an action. The three must be synchronized for change to occur. Timing 
is critical. Misalignments in time will result in failures. The Fogg model is presented in Figure 6.

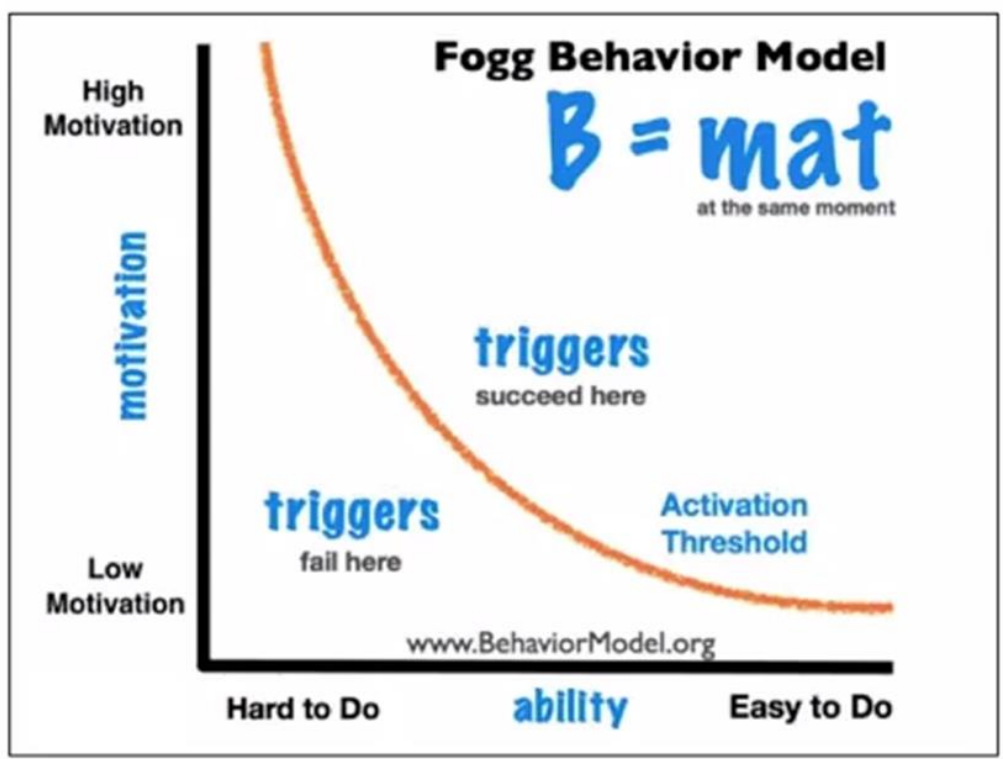

Figure 6: The Fogg model for human behavior change

(www.behaviormodel.org)

Motivation is placed in the vertical axis; ability is placed in the horizontal axis; and the trigger activation threshold is represented by the curved line. In general terms, the more motivated a user is to accomplish any given task, the more likely it is that the user will complete it. However, the Fogg model presents motivation in a tradeoff with the level of ability of the person. For example, if the task to be completed is too hard, then it will not be completed regardless of high the motivation is. Failures are therefore to the left of the activation threshold curve in the Fogg model. When the ability level meets a minimum of motivation then the trigger will result in success. The successes are therefore to the right of the activation threshold curve.

A user's real or perceived ability may be achieved in two ways. The first is through practice, which increases the real ability of the user until it exceeds the activation threshold required so that the action takes place successfully. Wu [19] adds the following regarding perceived ability: "a method of increasing a users' perceived ability is to make the target behavior simpler so that users require less ability to accomplish the behavior. This essentially lowers the activation threshold of the target behavior. For example: Divide and Conquer (break up a complex job into smaller and simpler tasks), Cognitive Rehearsal/Guidance (showing you how the job is done and how simple it is), Cascading Information (instructions and information are released in minimum snippets to guide 
you through a multi-stage task).. Wu is essentially describing methods to accomplish the

progression loops. The user would start with an easy task and would progressively build up while within the flow channel. The triggers are represented by classroom activities that would induce the students to continue climbing the steep path of knowledge. The activities should provide positive feedback. The activities (one-minute papers, short quizzes, formal exams, projects) must be given at exactly the right time in terms of students' ability and motivation to serve their intended purpose.

\section{Overview of MOOCs}

One of the hardest challenges that is faced by the faculty in applying innovations in the classroom is the amount of time required for the innovative activities. For example, a student will benefit greatly from handling a pair of pliers to learn how to sketch a free body diagram, idealize the forces applied by the hand, and do a statics analysis to the determine the squeezing force at the jaws; however, it takes time. One of the options being explored is to flip the classroom; i.e., have students watch videos outside of class (it becomes part of their homework), and use the classroom time to conduct innovative activities, to promote discussions, and to solve problems, all of which lead to deep learning of concepts (not easily forgotten). MOOCs are being considered as a potential avenue for flipping the classroom. In this model the student would register in the MOOC and watch the class videos outside of class. The first author enrolled in, and finished, three Coursera MOOCs during the first half of 2013 to experience firsthand its potential. There is a high potential, however, the faculty member must invest time to also watch the course videos and tailor his/her class to the MOOC.

\section{Innovate the exams and grading distribution}

As innovative teaching styles, such as the inductive methodology, are worked into the classroom, the exams and the grading distribution should also be innovated. Typical grading at this institution is heavily weighted towards traditional exams that were originally based on the more traditional, deductive style of teaching. Exams are certainly an important component as students get an opportunity to show the level that they have attained, and exams continue to be given but with one innovation: the faculty is now preparing a review sheet for each exam that includes the learning outcomes created during the SFIP. Students are instructed that they should be able to respond to any of them during an exam. The fact that a learning outcome, rather than a course topic, is required narrows down the requirements so students can better prepare for the tests. The requirements are narrowed because the action verb used in the outcome clearly defines the Bloom's taxonomy level that the student should have attained.

Also, the faculty are being recommended to place some grading weight on the innovative activities that they are conducting in class. There are opportunities to provide positive feedback 
by giving points for participating in the activities and achieving the desired goals of the activities. For example, if a student is given a light bulb, one wire, and a battery and asked to light the bulb, and they can accomplish it, some points may be given to the students as a positive feedback for being able to complete the activity, even if it took them several trials and errors before they finally figured it out. The fact that the student is engaged in the activity, and continues performing it until the goal is achieved, is a sign that there is motivation. As shown previously, motivation is a very important component in achieving engagement and in getting people to take action. These points assist in creating the engagement and progressive loops during class that could get students to climb the steep path of knowledge within the flow channel defined by Csikszentmihalyi. Some faculty are assigning approximately $20 \%$ of the grades to the innovative activities. Others are treating it as bonus points.

\section{$\underline{\text { Panoramic outline of each course prior to starting the SFIP in June }}$}

As a prerequisite (starting in 2013), each faculty member must complete a panoramic outline of each of the two courses before starting the SFIP in June (Table 2). The number of sessions used (30) corresponds to the number of times the class meets during the term. At Universidad del Turabo a term is defined as a 15-week semester and classes meet twice a week which results in 30 sessions. In total, 60 sessions are created (30 sessions per course). Each session must have at least one topic and some instructional objectives (a minimum of two or three). Table 2 may be used as a template for this exercise. The column labeled "Real-World Example", which establishes the context for the inductive methodology, is left blank to be addressed during the summer. If a topic appears to extend for more than one session it is simply repeated in the next session with perhaps different instructional objectives (or the same, depending on the case). The panoramic outline serves as the framework on which to transform the course. It forces each faculty member to take a broad and comprehensive view of the courses that they will address in the SFIP. At this stage there is no innovation. Setting the panoramic outline as a prerequisite leaves more time for innovation, a lesson learned during the 2012 SFIP session.

\section{Table 2: Template used to create a panoramic outline of 30 sessions of 1.5 hours each (a prerequisite to start the SFIP in June)}

\begin{tabular}{|c|c|c|c|}
\hline \multicolumn{3}{|c|}{$\begin{array}{c}\text { Course: } \\
\text { Professor: }\end{array}$} \\
\hline Session & Topic(s) & $\begin{array}{c}\text { Instructional Objectives - By the end of this session students shall be } \\
\text { able to: }\end{array}$ & $\begin{array}{l}\text { Real-World } \\
\text { Example }\end{array}$ \\
\hline 1 & & & $\begin{array}{l}\text { (Leave } \\
\text { blank until } \\
\text { SFIP starts) }\end{array}$ \\
\hline$\ldots$ & & & \\
\hline 30 & & & \\
\hline
\end{tabular}




\section{Partial Results}

The seven slots available for each summer SFIP session have filled up very quickly. All the faculty members that have participated have met the commitment of spending $100 \%$ of their time in June to this faculty development program. There have been a few exceptions where some extra load was present intermittently (a meeting, a conference presentation, personal issues). In those few cases, the SFIP period was extended and the faculty continued working into the first week of July until the deliverables were completed.

$100 \%$ of the 2012 SFIP participants implemented changes in the courses they taught; however, implementation has been gradual as is to be expected. Active learning techniques were used in $2 / 3$ of the lectures while real-world examples were developed inductively in $1 / 2$ of the sessions. Results from the 2013 SFIP group are not yet available. The survey for the 2013 group will be completed by the end of January 2014 .

In general, the faculty has liked working with the innovations in teaching and learning (4.5/5.0 in the survey of the 2012 SFIP). One issue that arose during the 2012 group was the issue of exams and that is being addressed with the review sheet and by revising the grading distribution to assign some weight to the activities. Another issue that arose was the time required to implement the activities during class. It is an issue that has yet to be resolved. One of the ideas that is being considered is flipping the classroom to provide "material coverage" in videos watched outside of class.

\section{Conclusions}

This paper has described the enhancements that were implemented in the 2013 edition of a Summer Faculty Immersion Program (SFIP). The program strives to ignite and sustain innovative classroom practices in engineering and physics courses in a manner that will promote lasting change in the faculty. In essence, the SFIP has been proposed as a mechanism to diffuse engineering education innovations in the classroom. Diffusion of educational innovations is a challenge that has defied a satisfactory solution for decades as evidenced by the many references in the literature. The paper included an exposition of the SFIP within Everett Rogers' theoretical framework of diffusion of innovations.

At this stage of implementation, the program shows potential to become an igniter for diffusing educational innovations; however, there are some issues to be solved. The most pressing issue is the class time required to implement the educational innovations. The flipped classroom is being evaluated as a possible alternative. 
Diffusion of educational innovations, in general, has not been an easy problem to solve. The problem has persisted for decades. The authors will continue making adjustments and enhancements over time to the SFIP as it faces obstacles and evolves to overcome them.

\section{Acknowledgments}

Funds for the Summer Faculty Immersion Program are provided by the US Department of Education, grant \#P031C110050.

\section{References}

[1] Borrego, M., Froyd, J.E., Hall, T.S. Diffusion of Engineering Education Innovations: A Survey of Awareness and Adoption Rates in U.S. Engineering Departments. Journal of Engineering Education. Vol. 99, Issue 3, July 2010, pages 185-207.

[2] National Research Council. Transforming Undergraduate Education in Mathematics, Engineering and Technology. National Academies Press, Washington, DC, 1999. Retrieved March 11, 2011, from http://www.nap.edu/openbook.php?record_id=6453\&page=R1

[3] Felder, R.M. and Hadgraft, R.G., Educational Practice and Educational Research in Engineering: Partners, Antagonists, or Ships Passing in the Night. Journal of Engineering Education. Volume 102, Issue 3, July 2013, pp. 339-345.

[4] Rogers, E., Diffusion of Innovations, $3^{\text {rd }}$ edition, The Free Press Publishing Co., New York, 1983.

[5] Morales, J.C. Implementing a Robust, yet Straightforward, Direct Assessment Process that Engages 100\% of the Faculty and Student Populations, Proceedings of the ASME International Mechanical Engineering Congress and Exposition, Florida, 2009.

[6] Ericsson, K. A.. Enhancing the development of professional performance: Implications from the study of deliberate practice. In K. Anders Ericsson, (Ed.), Development of professional expertise: Toward measurement of expert performance and design of optimal learning environments (pp. 405-431). New York, NY: Cambridge University Press.

[7] Litzinger, T.A., Lattuca, L.R., Hadgraft, R.G., Newstetter, W.C., Engineering Education and the Development of Expertise. Journal of Engineering Education. Vol. 100, No. 1, January 2011. Pp. 123-150.

[8] Morales, J.C. Summer Faculty Immersion: A Program with the Potential to Transform Engineering Education. HETS Online Journal. Volume II, Spring Issue: March 2012. http://www.hets.org/journal/articles/77-summerfaculty-immersion-a-program-with-the-potential-to-transform-engineering-education-

[9] Morales, J.C. and Prince, M.J. Summer Faculty Immersion as a Strategy to Diffuse Engineering Education Innovations: First Year Results. Proceedings of the 2013 ASEE Annual Conference, Atlanta, GA, June 2013. 
[10] Morales, J.C. Implementing a Robust, yet Straightforward, Direct Assessment Process that Engages 100\% of the Faculty and Student Populations, Proceedings of the ASME International Mechanical Engineering Congress and Exposition, Florida, 2009.

[11] Bloom, B.S. Taxonomy of Educational Objectives: Classification of Educational Goals; Handbook 1: Cognitive Domain. New York, Longman. 1956

[12] Albanese, M.A., and S. Mitchell, "Problem-Based Learning: A Review of Literature on its Outcomes and Implementation Issues," Academic Medicine, Vol. 68, 1993, pp. 52-81. (As cited in Reference [7] by Prince and Felder)

[13] Prince, M.J., and Felder, R.M. Inductive Teaching and Learning Methods, Journal of Engineering Education, April 2006.

[14] Werbach, K. For the Win: How Game Thinking Can Revolutionize Your Business. $1^{\text {st }}$ edition. Wharton Digital Press. 2012.

[15] Coursera MOOC course on Gamification. URL: https://www.coursera.org/course/gamification. Retrieved January 2, 2014.

[16] Wiki for Coursera Course on Gamification. URL: https://share.coursera.org/wiki/index.php/gamification002:Main. Retrieved January 2, 2014.

[17] Csikszentmihalyi, M. Finding Flow: The Psychology of Engagement with Everyday Life. Basic Books Publishing Co. 1998.

[18] BJ Fogg's Behavior Model, Stanford University. URL: http://www.behaviormodel.org/. Retrieved January 2, 2014.

[19] Michael Fu, The Magic Potion of Game Dynamics. URL: https://lithosphere.lithium.com/t5/science-of-socialblog/The-Magic-Potion-of-Game-Dynamics/ba-p/19260. Retrieved January 2, 2014. 